\title{
Studies on the damping properties of polyacrylate emulsion/hindered phenol hybrids
}

\author{
Xu Zhou, Guixin Zhang, Weizhou Zhang, Weihong Guo and Jikui Wang \\ Organic hybrids of polyacrylate emulsion (PAE)/hindered phenol (3,5-bis(1,1-dimethylethyl)-4-hydroxybenzenepropanoic acid \\ thiodi-2,1-ethanediyl ester, abbreviated as Irganox-1035) have been prepared in this study. The dynamic mechanical properties, \\ denoted by storage modulus $\left(E^{\prime}\right)$ and loss factor $(\tan \delta)$, of this binary system have been investigated. Dynamic mechanical \\ analysis (DMA) results show that by adding Irganox-1035, the tan $\delta$ peak maximum of the hybrids are remarkably increased up \\ to 4.2, demonstrating PAE/Irganox-1035 hybrids are promising damping materials. The damping mechanism of the hybrids has \\ also been systematically investigated through Fourier transform infrared spectroscopy (FTIR), differential scanning calorimeter \\ (DSC), X-ray diffraction (XRD), DMA and scanning electronic microscope (SEM). The experimental results indicate no hydrogen \\ bonding is formed between polyacrylate matrix and Irganox-1035 molecules and PAE has a good compatibility with Irganox- \\ 1035 existing in the amorphous form in the hybrids. Meanwhile, DMA results show amorphous Irganox-1035 has a super-high \\ viscoelastic property $(\tan \delta=20.7)$, which improves the damping performance of this compatible hybrids system.
} Polymer Journal (2012) 44, 382-387; doi:10.1038/pj.2012.6; published online 14 March 2012

Keywords: damping; hindered phenol; polyacrylate emulsion

\section{INTRODUCTION}

In many cases, vibrations are undesirable for structures due to the need for structural stability, position control, durability and noise reduction. ${ }^{1}$ Therefore, how to control and reduce vibrations is of great concern in modern society. Recently, damping coating was widely used to reduce vibrations with polyacrylate emulsion (PAE) an important component owing to its excellent bondability, weather ability, film-forming ability, mechanical property and low volatility as a low volatile organic compound. However, as a damping material, PAE also has its disadvantages, such as an improper glass transition temperature $\left(T_{\mathrm{g}}\right)$ for application and relatively lower damping peaks. Thus, many approaches have been used to improve its damping property. ${ }^{2}$ One of the most conventional ways is to mix several kinds of emulsions with different $T_{\mathrm{g} s}{ }^{3,4}$ This could broaden the damping temperature scope but decrease the intensity of the damping peak. An IPN (interpenetrating polymer network) has been conformed to be a very effective structure as high-performance damping materials,,${ }^{5,6}$ but the preparation of an IPN is relatively complicated and the cost is high. Addition of inorganic filler in a polymer matrix is another method to improve the damping behavior due to the friction between filler and chains of polymer. ${ }^{3}$

In recent years, a new concept based on a hybrid of bifunctional small molecules with polar polymer has drawn much attention. The earlier researchers found that the bifunctional molecules, such as
AO-60, AO-70, AO-80, AO-2246, can greatly improve the damping property of different polar polymers, such as chlorinated polyethylene, chlorinated polypropylene, acrylate rubber, ${ }^{7-12}$ hydrogenated nitrile butadiene rubber, ${ }^{13,14}$ carboxylated nitrile rubber, ${ }^{15}$ poly(vinyl chloride) and polyurethane. ${ }^{16}$ The improvement of damping property is mainly caused by the following factors: (1) the destruction and re-construction of reversible hydrogen bonding interactions between matrix polymers and hindered phenol results in a large consumption of energy during dynamic deformations; ${ }^{10,13}$ (2) the strong interactions between bifunctional small molecules and matrix enhances intermolecular friction and results in a large consumption of energy during dynamic deformations; $;^{17,18}$ (3) the excellent viscoelastic property of hindered phenol (the loss tangent of AO-80 $>26)^{14,19}$ also contributes to improvement of the damping property of the hybrids.

This study aims to prepare environmentally friendly coatings with high dynamical mechanical performance and study the mechanism of the damping improvement. PAE is chosen as the matrix, and the organic-hindered phenol 3,5-bis(1,1-dimethylethyl)-4-hydroxybenzenepropanoic acid thiodi-2,1-ethanediyl ester (Irganox-1035) with two hydroxyl groups is added to obtain a new organic hybrid system with high damping property. The damping properties of various PAE/Irganox-1035 hybrids have been investigated by dynamic mechanical analysis (DMA) and the damping mechanism have also been studied.

Polymer Alloy Laboratory, Shanghai Key Laboratory of Advanced Polymeric Materials, Key Laboratory for Ultrafine Materials of Ministry of Education, School of Materials Science and Engineering, East China University of Science and Technology, Shanghai, People's Republic of China

Correspondence: Dr J Wang, Shanghai Key Laboratory of Advanced Polymeric Materials, Key Laboratory for Ultrafine Materials of Ministry of Education, School of Materials Science and Engineering, East China University of Science and Technology, Shanghai 200237, People's Republic of China. E-mail: wang326@ecust.edu.cn

Received 5 October 2011; revised 13 December 2011; accepted 21 December 2011; published online 14 March 2012 
<smiles>CC(C)(C)c1cc(CCOC(=O)CCCCOC(=O)CCc2cc(C(C)(C)C)c(O)c(C(C)(C)C)c2)cc(C(C)(C)C)c1O</smiles>

Figure 1 Chemical structure of Irganox-1035.

\section{EXPERIMENTAL PROCEDURE}

\section{Materials}

The PAE (BA-163) with a solid content of $58 \pm 1 \mathrm{~m} / \mathrm{m} \%$ was manufactured by Beijing Eastern Acrylic Chemical Technology Corporation (Beijing, China). The organic-hindered phenol (Irganox-1035), in the form of crystalline powder, as shown in Figure 1, was manufactured by Ciba refinement (Shanghai, China) Co., Ltd.

\section{Sample preparation}

PAE/Irganox-1035 hybrids were prepared according to the following procedures and conditions: (1) Irganox-1035 powder was added into the PAE with the PAE/Irganox-1035 mass ratios of 100/0, 100/10, 100/30, 100/50 and 100/70. (2) The mixtures were stirred by a constant speed stirrer at a speed of 200-300 r.p.m. for $5 \mathrm{~min}$ and then dispersed by ultrasonic dispersion for $5 \mathrm{~min}$ (3) Mixtures were cured at room temperature for $24 \mathrm{~h}$, at $60^{\circ} \mathrm{C}$ for $12 \mathrm{~h}$ and finally at $80^{\circ} \mathrm{C}$ for $12 \mathrm{~h}$ separately. (4) Finally, the samples were cooled to room temperature.

Amorphous Irganox-1035 was obtained by means of melting initial Irganox1035 at $80^{\circ} \mathrm{C}$ for $30 \mathrm{~min}$ and then quenched at room temperature.

\section{Characterization and measurements}

DMA measurements of PAE/Irganox-1035 hybrids were carried out using a Dynamic Mechanical Analyzer (UBM Rheogel E4000, Kyoto, Japan) in a tension mode at a constant frequency of $11 \mathrm{~Hz}$ and a varied temperature from -50 to $100{ }^{\circ} \mathrm{C}$ with a heating rate of $3{ }^{\circ} \mathrm{C}$ per min. The parallelepiped specimens were $20 \mathrm{~mm}$ long, $5 \mathrm{~mm}$ wide and around $1.5 \mathrm{~mm}$ thick.

DMA measurements of amorphous Irganox-1035 were performed on the Dynamic Mechanical Analyzer (UBM Rheogel E4000) in a liquid shear mode at a constant frequency of $11 \mathrm{~Hz}$ and a varied temperature from -50 to $75^{\circ} \mathrm{C}$ with a heating rate of $3{ }^{\circ} \mathrm{C}$ per min.

The Fourier transform infrared spectroscopy (FTIR) spectra were obtained by scanning the specimens in the wave number range from 400 to $4000 \mathrm{~cm}^{-1}$ with a resolution of $2 \mathrm{~cm}^{-1}$ for 32 times on the Thermo Nicolet 5700 . The FTIR spectrum of quenched Irganox-1035 was obtained from the pressed ultrathin disk specimen made of amorphous Irganox-1035 and potassium bromide $(\mathrm{KBr})$, whereas the spectra of the hybrids was obtained from the film specimens with a thickness approximately $1 \mathrm{~mm}$ by using the Attenuated Total Reflection technique.

Differential scanning calorimeter (DSC) measurements were performed on the PC 200 calorimeter (NETZSCH Co., Shanghai, China). The DSC curves were recorded from -70 to $100^{\circ} \mathrm{C}$ with an increasing temperature rate of $10{ }^{\circ} \mathrm{C}$ per min.

Scanning electronic microscope (SEM) images were taken from the representative fracture surfaces of PAE/Irganox-1035 hybrids, using a Hitachi S-4800 apparatus (Hitachi, Singapore). Before SEM observations, liquid nitrogen-fractured surfaces of the hybrids were gold sputtered.

$\mathrm{X}$-ray diffraction (XRD) data recorded in the scattering angle of 5-80 were acquired from a Bruker D8 Advance X-ray diffractometer (Bruker, Karlsruhe, Germany).

\section{RESULTS AND DISCUSSION}

Dynamic mechanical properties of PAE/Irganox-1035 hybrids

Figure 2 shows the temperature dependence of storage modulus $\left(\mathrm{E}^{\prime}\right)$ of PAE/Irganox-1035 hybrids with various mass ratios. As shown in Figure 2, all the storage modulus curves display only one glass

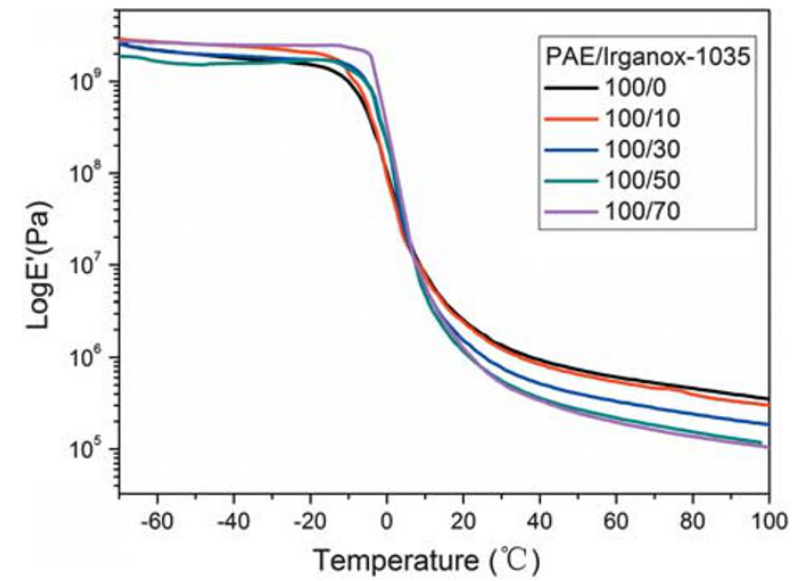

Figure 2 Temperature dependence of storage modulus $E^{\prime}$ for PAE and PAE/ Irganox-1035 hybrids.

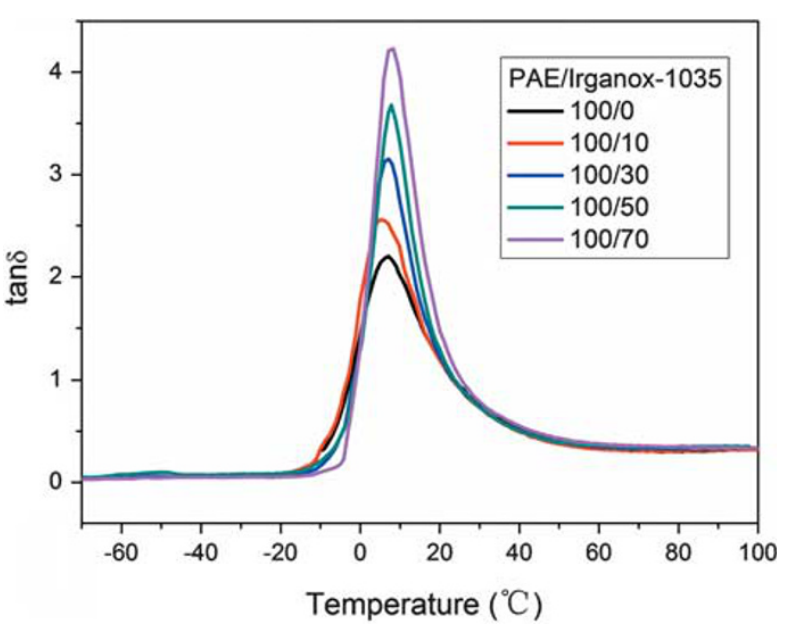

Figure 3 Temperature dependence of $\tan \delta$ at $11 \mathrm{~Hz}$ for PAE and PAE/ Irganox-1035 hybrids.

transition, which proves a good compatibility between PAE and Irganox-1035 as well as fine dispersion of Irganox-1035 in the PAE matrix. In this system, the $E^{\prime}$ values in the glassy region do not vary much, as the content of Irganox-1035 increases, whereas those in the rubbery region decrease significantly. It is observed, as in the glassy state, the modulus of amorphous Irganox-1035 is appropriate to the matrix and has little effect on the matrix's E'. However, when the testing temperature exceeds the glass transition temperature of Irganox-1035, it becomes soft and acts as a plasticizer, which decreases the $E^{\prime}$ value in the rubbery region of PAE/Irganox-1035 hybrids. ${ }^{17}$

The loss factor $(\tan \delta)$ is the crucial measure of material's damping property. The temperature dependence of $\tan \delta$ values of PAE/Irganox1035 hybrids with various mass ratios are shown in Figure 3. As only the macromolecular chain segments, not entire macromolecules, tend to vibrate, and the movement of molecular segments cannot keep up with the imposed vibration, thus an increase of the internal friction and energy dissipation is observed resulting in the appearance of the loss peak. The stronger the friction, the higher the $\tan \delta$ value and the better the damping performance. In this study, when the Irganox1035 amount in the PAE/Irganox-1035 hybrids increases from 0 to 
$70 \mathrm{phr}$, the $\tan \delta$ values increase from 2.2 to 4.2 , demonstrating that addition of Irganox-1035 could improve the hybrid's damping performance. In Figure 3, every single hybrid has only one $\tan \delta$ peak, which further supports that Irganox-1035 is compatible with PAE, and the dispersion of Irganox-1035 in the matrix is fine, even at high ratios of Irganox-1035 to PAE matrix.

\section{Damping mechanism}

From DMA results, it could be inferred that the hybrids' damping performance has been improved significantly by adding Irganox-1035. Therefore, the following discussions aim to clarify the damping mechanism of PAE/Irganox-1035 hybrids.

FTIR analysis of intermolecular interactions. Figure 4 shows the FTIR spectra of the amorphous Irganox-1035, PAE and the PAE/Irganox1035 hybrids. If it is the strong intermolecular interactions (hydrogen bonding) between the organic hindered phenol and the matrix that causes the high energy dissipation, then the hydrogen bonding must be observed in the infrared spectra. PAE and Irganox-1035 molecules contain three possible electron-donating groups capable of forming hydrogen bonding with hydroxyl groups: $\mathrm{O}-\mathrm{H}, \mathrm{C}=\mathrm{O}$ and $\mathrm{C}-\mathrm{O}-\mathrm{C}$.

Figure 4a shows the FTIR spectra of PAE, amorphous Irganox-1035 and PAE/Irganox-1035 hybrids at $4000-3100 \mathrm{~cm}^{-1}$, which corresponds to the hydroxyl group $(\mathrm{O}-\mathrm{H})$ stretching region. For pure PAE, no hydroxyl groups exist, thus no distinct infrared bands appear within $3450-3600 \mathrm{~cm}^{-1}$. For amorphous Irganox-1035, the infrared band of $\mathrm{O}-\mathrm{H}$ groups appears in a wide range, from 3485 to $3600 \mathrm{~cm}^{-1}$. The infrared band at $3640 \mathrm{~cm}^{-1}$ is assigned to free $\mathrm{O}-\mathrm{H}$ vibration of Irganox-1035 molecules; and the band at $3485 \mathrm{~cm}^{-1}$ is related to $\mathrm{O}-\mathrm{H}$ vibration affected by $\mathrm{OH}-\mathrm{OH}$ interactions (hydrogen-bonding) between Irganox-1035 molecules. Whereas for the PAE/ Irganox-1035 (100/10 and 100/50) hybrids, the infrared band at around $3485 \mathrm{~cm}^{-1}$ disappeared, the infrared band of $\mathrm{O}-\mathrm{H}$ groups only appears at around $3600 \mathrm{~cm}^{-1}$, which is assigned to free (nonhydrogen-bonded) $\mathrm{O}-\mathrm{H}$. With the increase of the Irganox-1035 amount, the intensity of the band at around $3600 \mathrm{~cm}^{-1}$ becomes stronger. These results indicate no hydrogen bonding formed between $\mathrm{O}-\mathrm{H}$ groups in the hybrids. The reason may be that the Irganox-1035 molecules are distributed evenly in the matrix and surrounded by polyacrylate molecules, therefore, Irganox-1035 molecules could not contact with each other.

Figure $4 \mathrm{~b}$ shows the FTIR spectra of PAE, amorphous Irganox-1035 and PAE/Irganox-1035 hybrids at $1800-1600 \mathrm{~cm}^{-1}$, which is attributed to the $\mathrm{C}=\mathrm{O}$ stretching region. For PAE/Irganox-1035 hybrids, the infrared band of $\mathrm{C}=\mathrm{O}$ groups clearly appears at $1725-1727 \mathrm{~cm}^{-1}$. Moreover, compared with pure $\mathrm{PAE}$, the $\mathrm{C}=\mathrm{O}$ band shifts to higher wave numbers, from 1724 to $1727 \mathrm{~cm}^{-1}$. It is well known that if the hydrogen bonding is formed between $\mathrm{C}=\mathrm{O}$ and $\mathrm{O}-\mathrm{H}$, it would reduce the characteristics of the $\mathrm{C}=\mathrm{O}$ and the band would shift to lower wave numbers. These opposite results demonstrate that no hydrogen bonding formed between the $\mathrm{O}-\mathrm{H}$ and $\mathrm{C}=\mathrm{O}$ groups.

Figure 4c shows FTIR spectra of PAE, amorphous Irganox-1035 and PAE/Irganox-1035 hybrids at $1200-1000 \mathrm{~cm}^{-1}$, which corresponds to the $\mathrm{C}-\mathrm{O}-\mathrm{C}$ symmetric and antisymmetric stretching region. Both bands hardly shift in the whole composition range, indicating that the hydroxyl of Irganox-1035 could not bond with the oxygen atom of C-O-C.

In previous studies, ${ }^{10,13}$ researchers found intercomponent hydrogen bonding is a key factor responsible for achieving a good damping property. It was concluded that the destruction and re-
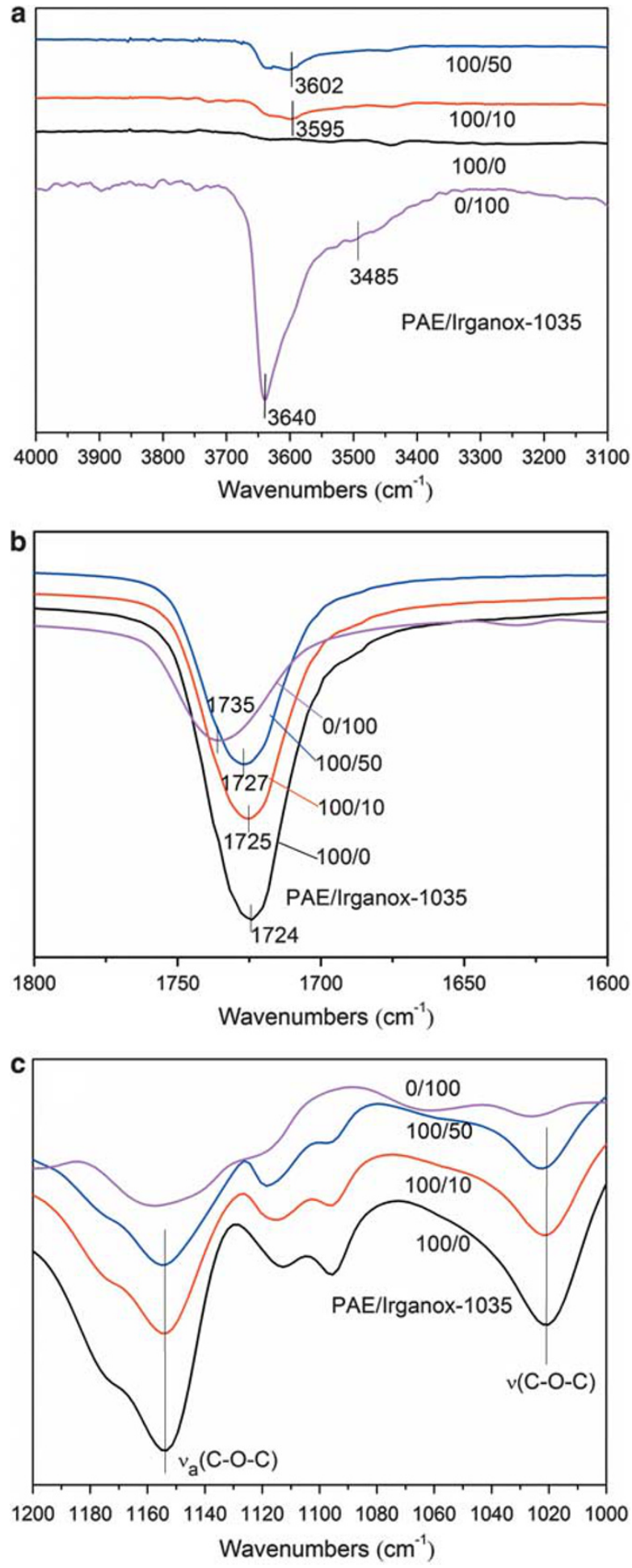

Figure 4 Infrared spectra of PAE, PAE/Irganox-1035 (100:10 and 100:50) and amorphous Irganox-1035 samples at (a) $4000-3100 \mathrm{~cm}^{-1}$; (b) $1800-1600 \mathrm{~cm}^{-1}$; (c) $1200-1000 \mathrm{~cm}^{-1} v$ and $v_{a}$ represent symmetric and antisymmetric stretching vibrations, respectively.

construction of hydrogen bonding caused high energy dissipation under dynamic deformation and thus improved the damping property. However, in this study, it is proved that no hydrogen bonding exists in the hybrids. Therefore, further studies have been 
carried out to investigate the damping mechanism of PAE/Irganox1035 hybrids.

Glass transitions and compatibility of PAE/Irganox-1035 hybrids. Figure 5 shows the DSC curves of the as received Irganox-1035, quenched Irganox-1035, neat PAE and PAE/Irganox-1035 hybrids, respectively. As shown in Figure 5a, the as received Irganox-1035 power is crystallized and the melting temperature is around $72.8^{\circ} \mathrm{C}$. After the as received Irganox-1035 is heated to $90^{\circ} \mathrm{C}$ and quenched to room temperature, the amorphous Irganox-1035 with a $T_{\mathrm{g}}$ about $-1.7^{\circ} \mathrm{C}$ is obtained.

As shown in Figure $5 \mathrm{~b}$, the $T_{\mathrm{g}} \mathrm{s}$ of the hybrids shift from -12.0 to $-8.2^{\circ} \mathrm{C}$, along with the content of Irganox-1035 increases from 0 to $70 \mathrm{phr}$ (parts per hundred of PAE by weight). All the DSC curves of the hybrids show only one $T_{\mathrm{g}}$ between the $T_{\mathrm{g}}$ of PAE and $T_{\mathrm{g}}$ of Irganox-1035, which indicates a good compatiblity between PAE and Irganox-1035. The DSC curves do not show the melting peak of Irganox-1035, which indicates that Irganox-1035 exists in amorphous form in the matrix after the curing process (also confirmed by XRD results).

The dependence of $T_{\mathrm{g}}$ on the composition of the miscible PAE/ Irganox-1035 hybrids has been illustrated in Figure 6. Over the years,
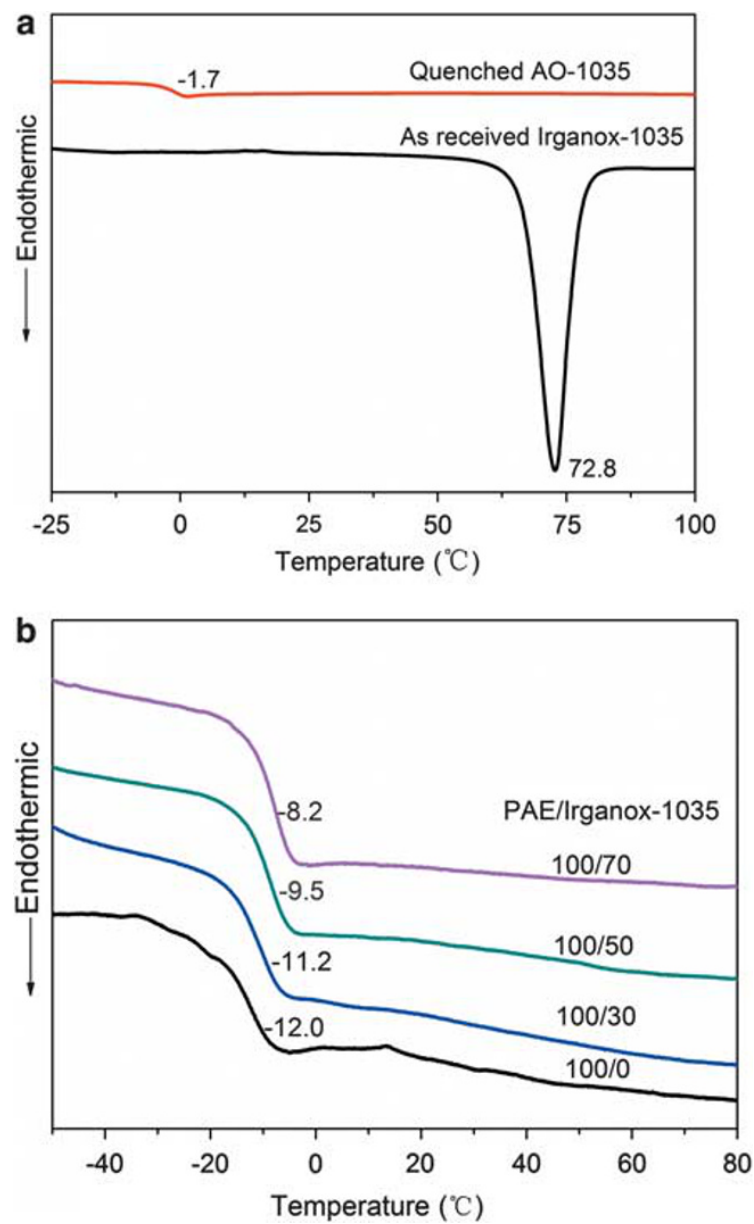

Figure 5 DSC curves of (a) neat Irganox-1035 and (b) PAE/Irganox-1035 hybrids. numerous equations have been proposed to express the $T_{\mathrm{g}}$-composition dependence in miscible polymer blends including expressions due to Fox, Gordon-Taylor, Couchman-Karasz, and Kwei. The most commonly employed expressions are Fox (equation 1) and GordonTaylor (equation 2):

$$
\begin{aligned}
& T_{\mathrm{g}}=\frac{w_{1}}{T_{\mathrm{g} 1}}+\frac{w_{2}}{T_{\mathrm{g} 2}} \\
& T_{\mathrm{g}}=\frac{w_{1} T_{\mathrm{g} 1}+k w_{2} T_{\mathrm{g} 2}}{w_{1}+k w_{2}}
\end{aligned}
$$

$w_{1}$ and $w_{2}$ are the weight fractions of component 1 and component 2, respectively; $T_{\mathrm{g} 1}$ and $T_{\mathrm{g} 2}$ are the respective $T_{\mathrm{g}} \mathrm{s}$ of the pure components. The $k$ parameter is often related to the strength of intermolecular interactions between the blend components. Positive deviations of linear behavior $(k=1)$ with the resultant high $k$ values are expected for blends with strong interactions between the components, and $T_{\mathrm{g}}$ observed for a hydrogen-bonded blend usually has a positive deviation. ${ }^{20} \mathrm{~A}$ negative deviation from linearity of the blend's $T_{\mathrm{g}}$ is often attributed to weak specific interactions. The predicted curves produced with the Gordon-Taylor equation have also been shown in Figure $6(k=0.83, k=0.64$ and $k=0.28$, respectively). As seen in Figure 6, the glass transition behavior of the hybrids demonstrates a negative deviation of the observed $T_{\mathrm{g}}$ from the linear $(k=1)$, which suggests weak specific interactions (nonhydrogen bonding) between PAE and Irganox-1035. With the increase of the Irganox-1035 amount, the $k$ value of the hybrids increases gradually. This indicates that the interaction between Irganox-1035 and PAE become stronger with an increase of Irganox-1035, which is favorable to the compatiblity of PAE matrix and Irganox-1035 molecules.

Morphology of PAE/Irganox-1035 hybrids. Figure 7 shows the SEM photograph of the fracture surfaces of PAE/Irganox-1035 (100/50) hybrid. The facture surface is smooth, and no particles corresponding to micro or nano dispersion of Irganox-1035 are observed. This phenomenon also indicates the favorable compatibility between PAE and Irganox-1035, and implies that Irganox-1035 molecules might

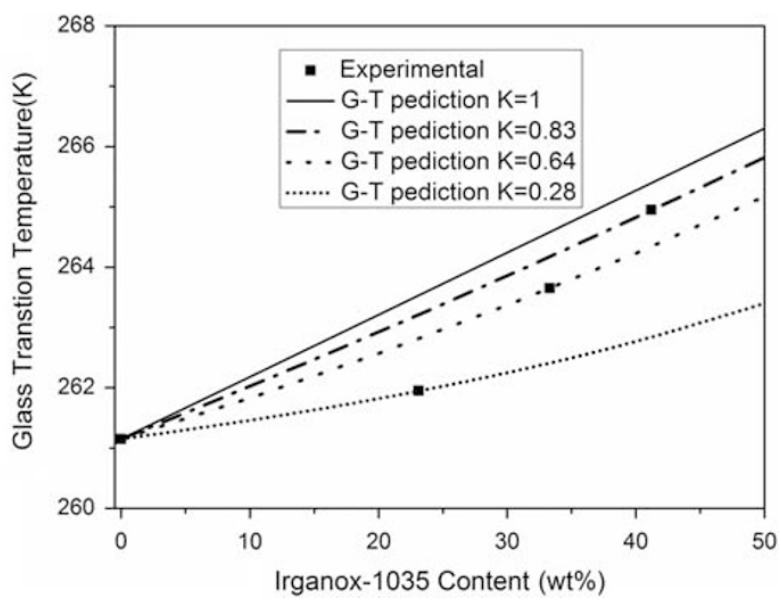

Figure 6 Glass transition temperatures of PAE//rganox hybrids as well as the Fox and Gordon-Taylor predictions with different $k$ values. 


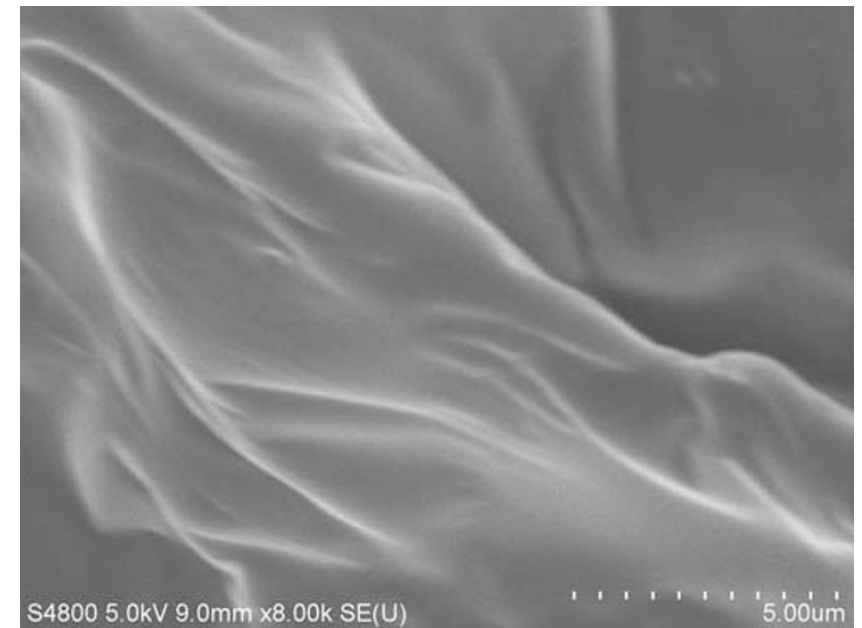

Figure $7 \mathrm{SEM}$ photographs of fracture surface of PAE Irganox-1035 (100/50) hybrid.

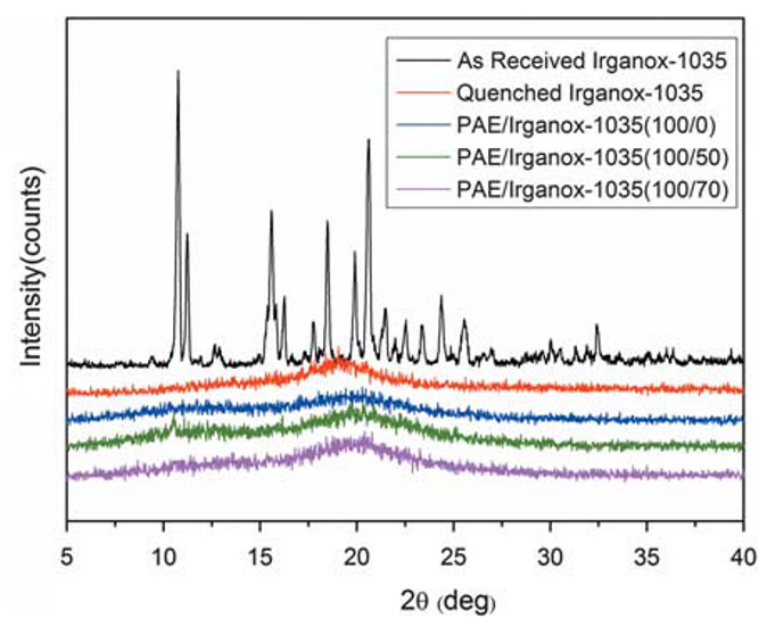

Figure 8 XRD curves of Irganox-1035 and PAE/Irganox-1035 hybrids.

disperse in PAE at the molecular level. ${ }^{16}$ This result further supports the above DSC and DMA discussion.

Crystallization of PAE/Irganox-1035 hybrids. Figure 8 shows the XRD curves of the PAE/Irganox-1035 hybrids as well as the quenched Irganox-1035, neat Irganox-1035 and PAE matrix. The as received and quenched Irganox-1035 displays typical crystalline and amorphous characteristics, respectively. The XRD traces of PAE/Irganox-1035 hybrids are similar to those of pure PAE and quenched Irganox-1035, demonstrating Irganox-1035 in the hybrids is also amorphous. Amorphous hindered phenol is a kind of viscoelastic material that has an excellent damping property. ${ }^{19}$

Dynamic mechanical property of amorphous Irganox-1035. The viscoelasticity of vitrified Irganox-1035 determined by DMA is shown in Figure 9. Figure 9 shows the temperature dependence of storage modulus $\left(\mathrm{G}^{\prime}\right)$ and loss factor $(\tan \delta)$ for amorphous Irganox-1035. Clearly, the modulus decreases promptly and tan $\delta$ increases sharply

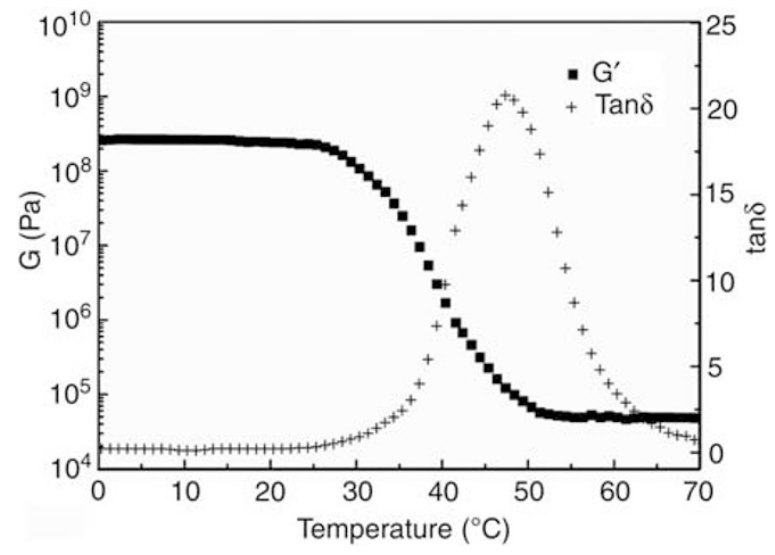

Figure 9 Temperature dependence of storage modulus and $\tan \delta$ at $11 \mathrm{~Hz}$ for amorphous Irganox-1035.

to 20.7 during glass transition. Also, the $\tan \delta$ of amorphous Irganox-1035 is much higher than any other polymers $(\tan \delta<3)$. This super-high damping property of amorphous Irganox-1035 leads to the improvement of the damping properties of this compatible hybrids system. It is interesting to find that the glass transition temperature of amorphous Irganox-1035 is about $47.5^{\circ} \mathrm{C}$ which is $49.3^{\circ} \mathrm{C}$ higher than the DSC results. This may be attributed to Irganox-1035 being closer to small molecules rather than polymers and there may be a special characteristic of Irganox1035 molecules that leads to the great differences between the DSC and DMA results. The same phenomenon has also been found in $\mathrm{AO}-80^{19,21}$ and $\mathrm{AO}-60 .^{22}$

\section{CONCLUSION}

A new organic hybrid PAE/Irganox-1035 system has been prepared based on the new design concept of organic hybrid damping materials. DMA results show that by adding Irganox-1035, the tan $\delta$ peak maximum of PAE is remarkably increased up to 4.2, demonstrating that PAE/Irganox-1035 hybrid is a promising damping material. The results of FTIR show no hydrogen bonding is formed between Irganox-1035 and PAE. Therefore, the damping improvement is not caused by destruction and reconstruction of hydrogen bonding under dynamic deformation. Through SEM and DSC analysis, PAE has a good compatibility with Irganox-1035, and Irganox-1035 molecules disperse in PAE at the molecular level. XRD results show that Irganox-1035 in hybrids exists in the amorphous form which has a super-high damping property $(\tan \delta=20.7)$. From these investigations, it can be concluded that the damping mechanism in PAE has a good thermodynamic compatiblity with Irganox-1035 and the excellent viscoelastic property of amorphous Irganox-1035 improves the damping property of the compatible hybrids system.

\section{ACKNOWLEDGEMENTS}

The authors sincerely acknowledge the National Key Technology R\&D Program of China (2008BAC46B10), the opening fund (No. 10zxbk06) of Engineering Research Center of Biomass Materials, Ministry of Education, Southwest University of Science and Technology, Mianyang, China and the University Student Renovation Project of China (101025122). 
1 Chung, D. D. L. Review materials for vibration damping. J. Mater. Sci. 36, 5733-5737 (2011).

2 Li, C., Wu, G. Z., Xiao, F. Y. \& Wu, C. F. Damping behavior of sandwich beam laminated with CIIR/petroleum resins blends by DMA measurement. J. Appl. Polym. Sci. 106, 2472-2478 (2007).

3 Ting, R. Y., Capps, R. N. \& Klempner, D. Effects of fillers on the acoustical properties of some IPN polymers. Polym. Mater. Sci. Eng 60, 654-658 (1989).

4 Wang, J. Y., Liu, R. Y., Li, W. H., Li, Y. W. \& Tang, X. Y. Studies on the damping performance of polystyrene/polyacrylate latex IPN. Polym. Int. 39, 101-104 (1996).

5 Chen, Q. M., Ge, H. H., Chen, D. Z. \& Yu, X. H. Investigation on damping behavior and morphology of polyurethane/polymethacrylates and polyacrylates interpenetrating polymer networks. J. Appl. Polym. Sci. 54, 1191-1197 (1994).

6 Zeng, W. \& Li, S. C. Effect of components (acrynitril and acrylate acid) on damping properties of poly(styrene-acrynitril)/poly(ethylacetate-n-butylacrylate) latex interpenetrating polymer networks. J. Appl. Polym. Sci 84, 821-826 (2002).

7 Wu, C. F., Yamagishi, T., Nakamoto, Y., Ishida, S., Nitta, K. \& Kubota, S. Viscoelastic properties of an organic hybrid of chlorinated polyethylene and a small molecule J. Polym. Sci. Pt. B-Polym. Phys 38, 1341-1347 (2000).

8 Wu, C. F., Yamagishi, T., Nakamoto, Y., Ishida, S., Nitta, K. \& Kubota, S. Organic hybrid of chlorinated polyethylene and hindered phenol. II. Influence of the chemical structure of small molecules on viscoelastic properties. J. Polym. Sci. Pt. B- Polym. Phys 38, 1496-1503 (2000).

9 Wu, C. F. Effects of a hindered phenol compound on the dynamic mechanical properties of chlorinated polyethylene, acrylic rubber, and their blend. J. Appl. Polym. Sci 80, 2468-2473 (2001).

10 Wu, C. F., Mori, K., Otani, Y., Namiki, N. \& Emi, H. Effects of molecule aggregation state on dynamic mechanical properties of chlorinated polyethylene/hindered phenol blends. Polymer 42, 8289-8295 (2001).

11 Wu, C. F., Yamagishi, T., Nakamoto, Y., Ishida, S., Nitta, K. \& Kubota, S. Organic hybrid of chlorinated polyethylene and hindered phenol. I. Dynamic mechanical properties J. Polym. Sci. Pt. B-Polym. Phys 38, 2285-2295 (2000).
$12 \mathrm{Wu}, \mathrm{C}$. F. Organic hybrid of chlorinated polyethylene and hindered phenol. IV. Modification on dynamic mechanical properties by chlorinated paraffin. J. Polym. Sci. Pt. B-Polym. Phys 39, 23-31 (2001).

13 Cao, Y. Y., Mou, H. Y., Shen, F., Xu, H. Y., Hu, G. H. \& Wu, C. F. Hydrogenated nitrile butadiene rubber and hindered phenol composite. II. Characterization of hydrogen bonding. Polym. Eng. Sci. 51, 201-208 (2011).

$14 \mathrm{Cao}$, Y. Y. Hydrogenated nitrile butadiene rubber and hindered phenol composite. I. Miscible and dynamic mechanical property. Polym. Eng. Sci. 50, 2375-2381 (2010).

15 Liu, Q. X., Ding, X. B., Zhang, H. P. \& Yan, X. Preparation of high-performance damping materials based on carboxylated nitrile rubber, combination of organic hybridization and fiber reinforcement. J. Appl. Polym. Sci. 114, 2655-2661 (2009).

16 Xiao, D. L., Zhao, X. Y., Feng, Y. P., Xiang, P., Zhang, L. Q. \& Wang, W. M. The structure and dynamic properties of thermoplastic polyurethane elastomer/hindered phenol hybrids. J. Appl. Polym. Sci. 116, 2143-2150 (2010).

17 Xiang, P., Zhao, X. Y., Xiao, D. L., Lu, Y. L. \& Zhang, L. Q. The structure and dynamic properties of nitrile-butadiene rubber/poly(vinyl chloride)/hindered phenol crosslinked composites. J. Appl. Polym. Sci. 109, 106-114 (2008).

18 Zhao, X. Y. Nitrile butadiene rubber/hindered phenol nanocomposites with improved strength and high damping performance. Polymer 48, 6056-6063 (2007).

19 Cao, Y. Y., Li, Q. Y., Zhang, L., Wu, G. Z. \& Wu, C. F. Viscoelasticity of a vitrified hindered phenol compound during thermal annealing. J. Non-Cryst. Solids. 353, 4232-4235 (2007).

$20 \mathrm{He}$, Y., Zhu, B. \& Inoue, Y. Hydrogen bonds in polymer blends. Prog. Polym. Sci. 29, 1021-1051 (2004).

$21 \mathrm{Li}, \mathrm{C}$. Study on high performance damping materials from chlorinated butyl rubber systems and the application on the constrained layer damping structure, 23-25, (Doctoral Dissertation, Shanghai, 2007).

22 Cao, Y. Y. Polymorphous of hindered phenol and preparation of polymer/hindered phenol damping hybrid, 25-27, (Doctoral Dissertation, Shanghai, 2010). 